\title{
"Who to Cultivate?": A Study on the Changes in Primary School Language Education Goals in the Curriculum Documents
}

\author{
Fei Geng, Cuilan Zhao* \\ Teachers College, Qingdao University, Qingdao 266000, Shandong Province, China \\ *Corresponding author: Cuilan Zhao, qdhdzcl@163.com
}

\begin{abstract}
What kind of person is the root of education? What kind of person embodies the essence of education and the direction of education? The goal of education cannot be solved without specific courses and disciplines. This study is carried out to characterize the Chinese curriculum standards (syllabus), review the founding of New China over 70 years of primary school Chinese curriculum, and outline an education picture from the "curriculum" itself to "individual students," from "single" to "compound," and from "present" to "future." It has been concluded that the pursuit of national characteristics, the exploration of a wholesome personality, and the prospect of new people of the times are the internal evolution logics of primary school Chinese education.
\end{abstract}

Keywords: Chinese course; Curriculum standards; Education goals

Publication date: December 2021; Online publication: December 27, 2021

\section{Research problem}

For the first time in the history of pedagogy, The Taxonomy of Educational Objectives, written by Benjamin Bloom, is an innovative system for specifying educational goals ${ }^{[1]}$. The solution to this problem should be implemented in specific disciplines. The Chinese subject has its own particularity. It does not only include basic language tools, such as listening, speaking, reading, and writing, but also natural ideological and moral values. As the fundamental stage for mastering the laws of language and writing as well as cultivating literacy skills, the primary school stage is a critical period for forging Chinese literacy and quality. The Chinese curriculum standards (syllabus) are based on people's understanding of Chinese education in a certain historical period. Based on this, the historical changes of the Chinese education goals in primary schools since the founding of the People's Republic of China and the 70 years of primary school Chinese education are discussed. The goal is to develop mirror images, hoping to provide reference for better realization of the educational value of Chinese courses.

\section{Research basis}

Professional courses are important carriers to realize the educational goal (three-dimensional objective) and to help college students construct the socialist core value system ${ }^{[2]}$. Among them, the question of what kind of person to train is also described in detailed and the requirements of talent quality are put forward. Therefore, this study explores the primary school Chinese education goals based on the curriculum documents; namely, the primary school Chinese curriculum standards (syllabus), in order to provide strong practical support. A total of 12 primary school Chinese curriculum standards (syllabus) have been selected as the subjects for analyses in this study, taking the expression of educational goal in the curriculum 
standards as the observation point and the 70 years since the founding of New China as the time pedigree in aiming at analyzing the core problem of who should be cultivated in regard to the Chinese curriculum of primary schools in China.

\section{Changes in the education goal of primary school Chinese curriculum}

Since the founding of the People's Republic of China, the curriculum standards of primary school Chinese have experienced different stages over time, and the educational goal of the curriculum standards in each stage has highlighted different characteristics. Taking time as the axis, and according to the evolution path of its curriculum standards (syllabus), this study divides the evolution of primary school education goals into three stages since 1949, so as to clarify the education law of the Chinese curriculum in primary schools over different periods in China.

\subsection{0-1963: Cultivating people with distinct ideological and political consciousness}

After the founding of the People's Republic of China, the question of what kind of people to train has become a serious proposition that needs to be solved urgently in various disciplines. The educational goal of the Chinese curriculum in primary schools emphasizes on ideological and political nature. At present, the primary school Chinese curriculum emphasizes the ideological nature of educating people. Therefore, at this stage, there is a pull between ideology and knowledge, with ideology finally occupying an absolute advantage, resulting in the confusion, complexity, and difficulty of the Chinese curriculum in the goal of educating people.

\subsection{8-1999: Cultivating people with both knowledge ability and moral accomplishment}

After 1978, the order of education was gradually restored. At this stage, the answer to the question of "Who to cultivate?" in regard to primary school Chinese curriculum shows the tendency of a two-way unification: instrumentality and ideological nature. The educational orientation of the Chinese curriculum in primary schools comprises of two dimensions: the goal of knowledge ability and the goal of moral accomplishment.

Since the reform and opening-up, the value of Chinese education in primary schools has become richer. In terms of knowledge, it does not only cultivate people with language knowledge ability, but also "perfect people" with good logic, observation, imagination, and aesthetic interest, thus meeting the basic function and ultimate orientation of the curriculum standards. In terms of moral goals, primary school Chinese is devoted to cultivating people who recognize the socialist system and the socialist motherland, who love and inherit the great national spirit, as well as those who have good personal cultivation and moral quality.

\subsection{1-present: Cultivating people needed by the future society}

The educational goal of the Chinese curriculum in primary schools in the new century is adapting to the changes and requirements of the new era, in which its vision and pattern are broader and higher. In the $21 \mathrm{st}$ century, primary school Chinese curriculum should cultivate people who do not only focus on the present, but also have sound personalities and Chinese literacy. The Chinese curriculum should also be more futureoriented; that is, to cultivate people who can adapt to the future society and have national characteristics.

The modernization goal in education is to create a mechanism for the sustainable development of the education system ${ }^{[3]}$. The evolution of the education goal of the Chinese curriculum in primary schools reflects the social expectation and demand for talents. Through analysis, it can be concluded that primary school Chinese has adjusted and responded positively to the challenge of cultivating new talents. The cultivation of talents emphasizes more on the future society and lifelong development, while the role of 
Chinese as an ideological and political tool is gradually weakening. In terms of cultivating students' personalities and key abilities, it is no longer just simple knowledge and skills as well as basic moral character ${ }^{[4]}$; the goal of educating students is now turning toward social emotion and social ability, and it is committed to cultivating complete individuals who are able to cope with the complex and changeable future society. At this stage, the people trained in primary school Chinese are those needed by the future society, and the goal of education has begun to be grounded on students' subjectivity and lifelong development.

\section{Conclusion and enlightenment}

Since the founding of New China 70 years ago, with the growth and development of New China, the Chinese curriculum as a comprehensive and practical basic subject, has experienced various modifications and enrichment. The answer to the question of "Who to cultivate?" has realized the exploration and growth path from "curriculum" to "individual students," from "single" to "compound," and from "present" to "future." If the purpose of education is to enable the students to appear as the subjects, plurality becomes an important prerequisite in education ${ }^{[5]}$. On the whole, the exploration of the aforementioned question has been enriched, reflecting the characteristics of integrity, stability, and scientificity. Specifically, the internal evolution logic of "Who to cultivate?" is discussed below.

(1) Pursuit of national characteristics

The primary or basic goal is the continuous pursuit of national characteristics, which is mainly reflected in patriotism and socialist morality. Descriptions such as "communist morality," "cultivating the spirit of patriotism," and "strengthening the socialist faith" in the Chinese curriculum standards (syllabus) reflect the establishment and guarantee of national characteristics among the people they cultivate. Primary school Chinese undertakes the great mission of cultivating and carrying forward the national spirit as well as strengthening patriotism; in addition, its function has also been given full play.

(2) Exploration of a wholesome personality

The rapid development of the society calls for a wholesome personality; therefore, the Chinese curriculum in primary schools emphasizes more on students' individual growth in terms of education, aiming to help students become real subjects through the curriculum. The teaching content, classroom organization, situation, and educational target of the Chinese curriculum should all point to individual development; only in this way can the educational function of curriculum be truly implemented. The "three-dimensional objective" in the compulsory education curriculum standard in 2001 emphasizes on children's learning experience and emotional changes, indicating that the educational goal of the Chinese curriculum focuses on the overall and comprehensive development of students. From this point of view, the education goal of the Chinese curriculum in primary schools is to cultivate the comprehensive quality and wholesome personality that future social citizens should have.

(3) Prospect of new people of the times

The fundamental requirement of the curriculum in primary and secondary schools is to promote the socialization of the new generation, making them the main body of the society. Primary school Chinese, as a basic compulsory education, has an unavoidable responsibility and arduous mission to promote the socialization of a new generation of children. The Chinese curriculum in primary schools points to the future society and cultivates talents in line with the spirit of the times and lifelong development. The research on the core literacy of student development in the 21 st century, published 
in 2016, clearly pointed out the essential character and key abilities that students should possess to adapt to lifelong development. The Chinese curriculum standards in 2011 also urged to lay a foundation for students' lifelong development. It can be seen that the education goal of the Chinese curriculum is consistent with the national education goal.

Finally, the answer to the question of "Who to cultivate?" in regard to primary school Chinese curriculum does not only point to human development, which includes the cultivation of students' values, key abilities, and essential characters, but also emphasize on the future society, where the goal is directed toward political life, social progress, and lifelong development. Over a period of 70 years, primary school Chinese curriculum has grew increasingly rich connotations; its vision is becoming wider, from the initial political tool with one-sided emphasis on language performance to ideological content and instrumental two-dimensional cultivation with more emphasis on individuals. New talents in the new century should possess the ability of literacy. With the progress and development of the times, the Chinese subject in primary schools would face more challenges in education along with its development. How then to better realize the value of education and play a role in the future of primary school Chinese curriculum? This would provide reference for the majority of education researchers and trigger more thinking.

\section{Disclosure statement}

The authors declare that there is no conflict of interest.

\section{References}

[1] Tatik A, Edi H, Tahrun, 2021, The Competency of State Elementary School Teachers in Mastering Digital Literation. Advances in Social Science, Education and Humanities Research, 565: 835-838.

[2] Feng J, Zhao J, Zhang X, et al., 2020, Design and Exploration of Ideological and Political Education in the Course of "Computer Network Principle". Advances in Social Science, Education and Humanities Research, 480: 688-691.

[3] Martynenko EV, 2020, Russian Educational System in the Context of Structural Reforming Crucial Goals and Problems of Transformation. Advances in Economics, Business and Management Research, 128: 1054-1061.

[4] Sun S, 2020, Research and Practice of Mathematics Culture Education with the Purpose of Improving College Students' Comprehensive Quality. Advances in Social Science, Education and Humanities Research, 496: 1149-1152.

[5] Portin F, 2020, The Diplomatic Teacher: The Purpose of the Teacher in Gert Biesta's Philosophy of Education in Dialogue with the Political Philosophy of Bruno Latour. Studies in Philosophy and Education, 2020: 1-16. 